\title{
Desain Interior "Restoran Bebek Sinjay Madura" Berkonsep Tradisional dengan Pendekatan Budaya Madura
}

\author{
Afridatul Auliyah, Budiono \\ Departemen Desain Interior, Fakultas Teknik Sipil dan Perencanaan, Institut Teknologi Sepuluh \\ Nopember (ITS) \\ Jl. Arief Rahman Hakim, Surabaya 60111 \\ E-mail: budiono@interior.its.ac.id, afridatula@gmail.com
}

\begin{abstract}
Abstrak - Bisnis restoran di Pulau Madura mulai berkembang khususnya Restoran yang menyajikan menu bebek, Restoran Bebek Sinjay merupakan salah satu restoran bebek yang berasal dari Madura yang saat ini mulai mengembangkan bisnisnya dengan membuka cabang. Namun, perkembangan bisnis restoran ini tidak didukung dengan perbaikan fasilitas restoran. Masalah lain yang penulis temukan pada restoran Bebek Sinjay yaitu tidak adanya karakteristik khusus yang menunjukkan ciri khas restoran dan tidak terciptanya privasi antar kelompok pengunjung.dari beberapa masalah yang ditemukan maka disusun metode desain.

Metode desain dalam hal ini dapat dilakukan melalui dua tahap yaitu pengumpulan data dan tahap analisa data. Tahap pengumpulan data berupa observasi (wawancara karyawan, kuisioner online untuk pelanggan, dan survey restoran Bebek Sinjay) dan studi literatur. Untuk tahap analisa meliputi studi eksisting berupa analisa aktivitas dan kebiasaan pengunjung, kebutuhan ruang, studi pembanding, sirkulasi, corporate image, dan fasilitas.

Dari pengolahan data dan analisa tersebut diharapkan dapat menghasilkan sebuah desain interior restoran yang nyaman dan memiliki ciri khas sebagai restoran yang berasal dari Madura dengan mengangkat budaya Madura sehingga dapat menarik pengunjung sekaligus dapat menambah manfaat dan edukasi bagi masyarakat.
\end{abstract}

Kata Kunci- Budaya Madura, Interior restoran, Restoran Bebek Sinjay.

\section{PENDAHULUAN}

INDUSTRI kreatif merupakan salah satu faktor yang menjadi $\mathbf{I}_{\text {penggerak perekonomian nasional. Di Indonesia, industri }}$ kreatif dibagi menjadi 15 sektor salah satunya kuliner. Kuliner merupakan salah satu industri yang berkembang pesat di Indonesia, tidak heran jika saat ini tak terhitung berapa banyak restoran atau rumah makan yang berdiri di Indonesia sosial dapat diterima lingkungannya, dan menghindari apa yang dilarangnya.

Mulai dari industri kuliner yang berbasis usaha kecil menengah hingga restoran mewah yang menyajikan hidangan hidangan dengan harga selangit. Saat ini restoran menjadi salah satu bisnis yang banyak diminati oleh masyarakat, karena selain menghasilkan keuntungan yang tinggi, makanan juga menjadi kebutuhan pokok bagi setiap orang. Hal tersebut bisa dilihat pada perekenomian Indonesia pada tahun 2012 yang mengalami peningkatan di setiap sektor. Pertumbuhan di bidang perdagangan, hotel, dan restoran merupakan sektor yang mengalami peningkatan tertinggi kedua, mencapai 8,11 persen (www.bps.go.id).

Semakin berkembang dan meningkatnya bisnis restoran memunculkan persaingan bisnis yang mengakibatkan setiap restoran dituntut untuk dapat memberikan layanan yang terbaik bagi konsumen. Mulai kualitas dan cita rasa makanan yang disajikan, hingga desain interior ruang makan juga perlu diperhatikan. Hal ini dilakukan untuk menarik minat konsumen yang pertama kali mengunjungi atau belum mengenal restoran tersebut, sehingga pengunjung puas dan kembali lagi ke restoran tersebut. Desain Interior dalam restoran sangat penting untuk memaksimalkan tingkat kepuasan pelanggan dan mengoptimalkan kerja para karyawan. Ruang makan yang fungsional, optimal, menyenangkan, serta menunjukkan identitas dari restoran tersebut akan membuat pelanggan lebih mengingat restoran tersebut dan memutuskan untuk kembali lagi. Untuk itu dibutuhkan sebuah desain interior yang dapat mengimplementasikan identitas restoran serta memberikan rasa nyaman bagi pengunjung, karyawan, dan seluruh pengguna yang terkait. Akan tetapi di daerah tertentu masih banyak restoran yang kurang memperhatikan kenyamannan dan kualitas restoran tersebut, salah satunya di Pulau Madura.

Pulau Madura bisa dikatakan, pulau yang sedang berkembang karena hal ini didukung oleh adanya prasarana transportasi Jembatan Suramadu juga menjadi Peluang, yang menjanjikan karena Madura Khususnya Bangkalan adalah kabupaten yang sangat dekat dengan Surabaya, itu berpengaruh kepada kunjungan wisatawan untuk berkunjung ke Madura. Banyaknya wisatawan yang berkunjung ke Madura menyebabkan peluang bisnis retoran di Madura dan persaingan antar restoran juga semakin menigkat baik dalam hal pelayan maupun desain interior restoran, akan tetapi masih banyak pebisnis restoran yang kurang memanfaatkan budaya Madura sebagai desain interior yang menggambarkan identitas retoran, salah satunya retoran Bebek Sinjay.

Restoran Bebek Sinjay memiliki masalah utama yaitu fasad bangunan yang kurang layak dijadikan restoran, sehingga restoran ini tampak seperti kumuh dan tidak nyaman bagi pengunjung. Selain itu, jarak antar kursi terlalu sempit sehingga privasi pengunjung dan sirkulasi restoran kurang nyaman. Tidak adanya variasi tempat duduk atau area 
menyebabkan restoran terlalu monoton, oleh karena itu perlu adanya variasi area seperti area lesehan dan area VIP serta variasi jumlah kursi agar terlihat lebih menarik. Masalah lain yang tidak kalah pentingnya yaitu letak restoran Bebek Sinjay yang berada di Pulau Madura dan tidak memiliki identitas restoran seharusnya perusahaan dapat memanfaatkan budaya lokal Madura sebagai identitas Restoran Bebek Sinjay, sehingga pengunjung dapat menikmati sajian makan sekaligus memperoleh pengetahuan dan hiburan. Berdasarkan masalah yang penulis temui maka konsep desain interior restoran Bebek Sinjay yang diajukan penulis yaitu Desain Interior Restoran Bebek Sinjay Berkonsep Tradisional Dengan Pendekatan Budaya Madura.

\section{A. Rumusan Masalah}

1. Restoran Bebek Sinjay belum memiliki karakter khas sebagai restoran yang berasal dari Madura

2. Sistem pemesanan yang kurang efektif sehingga mengakibatkan sirkulasi pada area makan dan area kasir kurang nyaman.

3. Belum adanya fungsi kenyamanan ruang untuk menciptakan kesan ekslusif pada area VIP.

\section{B. Tujuan}

1. Menciptakan desain interior restoran Bebek Sinjay agar memiliki identitas dan karakteristik yang khas dan berbeda sehingga mudah diingat pengunjung dan menarik minat pengunjung untuk kembali lagi.

2. Menciptakan layout interior yang nyaman sehingga sirkulasi pada area kasir tidak mengganggu area makan.

3. Menciptakan desain restoran Bebek Sinjay yang nyaman dan dapat tercipta privasi antar kelompok pengunjung.

4. Menciptakan desain Interior restoran Bebek Sinjay yang mendukung fungsi kenyamanan ruang untuk memunculkan kesan eklusif pada Area VIP restoran Bebek Sinjay

\section{STUDI PUSTAKA}

\section{A. Desain Tradisional}

Desain tradisional merupakan suatu desain yang mengangkat hasil budaya dari suatu daerah yang disajikan pada sebuah ruang atau bangunan, baik pada elemen interior maupun elemen desain.

Menurut majalah rooang mengenai desain tradisional ada 7 ciri diantaranya :

- Suasana Homey

- Pola bunga sulur sesuai dengan budaya yang diangkat

- Penggunaan warna dan material alam.

- Furnitur dan elemen interior lainnya dihadirkan secara berpasangan

- Bentukan halus dan lengkung.

- Konsisten, teratur, dan detail.

\section{B. Budaya Madura}

Menurut Rasul Junaidy masyarakat madura memiliki tiga nilai yang sangat menjadi acuan berpikir dan bertindak, ketiga nilai tersebut di tuangkan kedalam unsur - unsur prilaku kehidupan sehari - hari yaitu , agama , kekerabatan, dan kesenian.

Karapan sapi merupakan salah satu hasil budaya Madura dalam bentuk kesenian yang hingga saat ini sangat dikenal dikalangan masyarakat Madura maupun luar maduran. Didalam karapan sapi terdapat beberapa hasil budaya Madura diantaranya, ukiran dan warna khas Madura.

\section{URAIAN PENELITIAN}

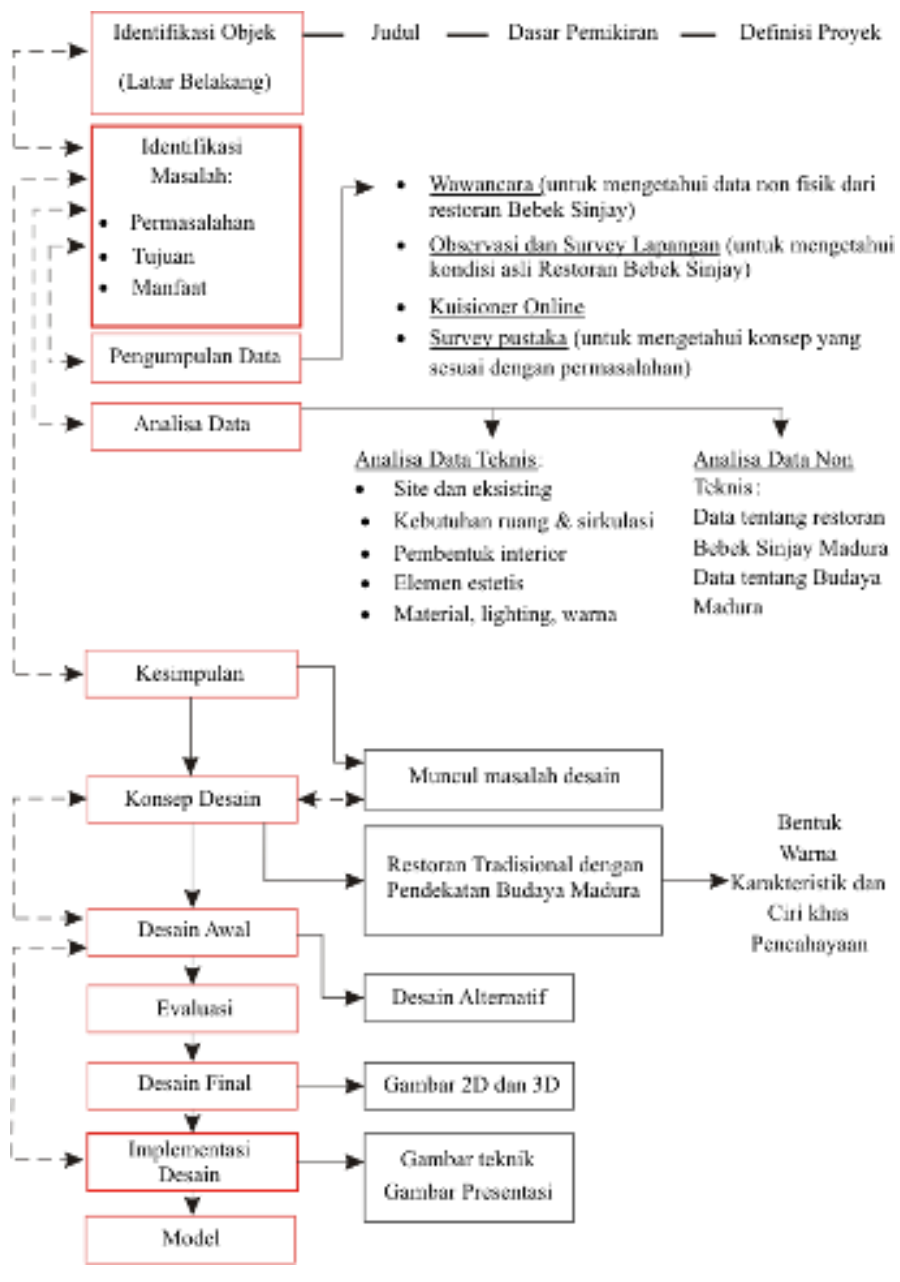

Gambar 1. Alur Desain

(Sumber : Dokumen Pribadi)

Metode desain dalam menuju desain akhir memiliki urutan proses sebagai berikut:

1. Pengumpulan Data, jenis-jenis data yang digunakan dalam metode penelitian adalah: a) data primer: data internal dari pihak rumah sakit, b) data observasi: data yang didapat penulis dari observasi langsung, dan c) data kuesioner: data analisa hasil riset.

2. Analisa Data, metode analisa yang digunakan adalah analisa induktif, deskriptif dan komparatif dengan mengolah data yang telah didapat.

3. Kesimpulan, proses pembentukan hasil analisa data dengan menyesuaikan studi literature menjadi konsep desain. Proses desain dilakukan dengan membentuk gagasan 
desain berupa konsep makro dan mikro

4. Proses Desain, proses pembentukan konsep desain menjadi desain nyata. Proses desain kemudian dilanjutkan dengan pembuatan alternatif desain, sketsa dan gambar kerja.

5. Desain Akhir, perwujudan dari konsep desain menjadi presentasi desain.

\section{KONSEP DESAIN}

\section{A. Objek Desain}

Objek desain interior merupakan sebuah restauran keluarga yang terletak di Bangkalan, Madura.

\section{B. Tema}

Tema pada desain adalah Tradisonal dengan pendekatan budaya Madura yang diterapkan pada desain interior restoran. Konsep tradisional diterapkan pada penggunaan material. Karakter tema yang digunakan berupa penggunaan elemen interior dan pengaplikasian ukiran, warna, ragam hias pada interior.

\section{Konsep Desain}

Secara keseluruhan konsep yang diterapkan pada desain interior restauran Bebek Sinjay adalah menciptakan desain interior hotel dengan budaya madura yang kemudian dikembangkan berdasarkan latar belakang, permasalahan, dan tujuan. Sesuai dengan konsep awal, pengaplikasian konsep akan diterapkan pada interior ruang.karakter Madura yang dikembangkan adalah rumah khas Madura dan karapan sapi.

\section{Aplikasi Konsep Desain}

1) Konsep Ruangan

Restoran berdiri diatas lahan seluas $900 \mathrm{~m}^{2}$.

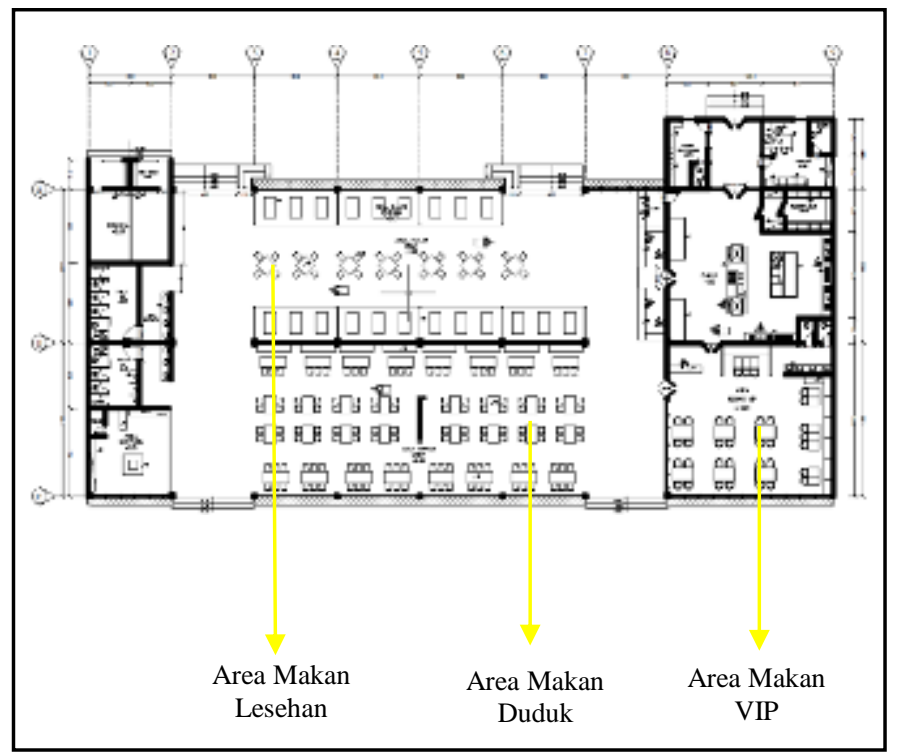

Gambar 2. Layout Terpilih

(Sumber : Dokumen Pribadi)
Gambar diatas merupakan layout terpilih dari tiga alternatif layout yang dibuat, layout tersebuat dipilih berdasarkan standart ergonomi dan sirkulasi ruang yang pas untuk restoran Bebek Sinjay.

\section{2) Konsep Bentuk}

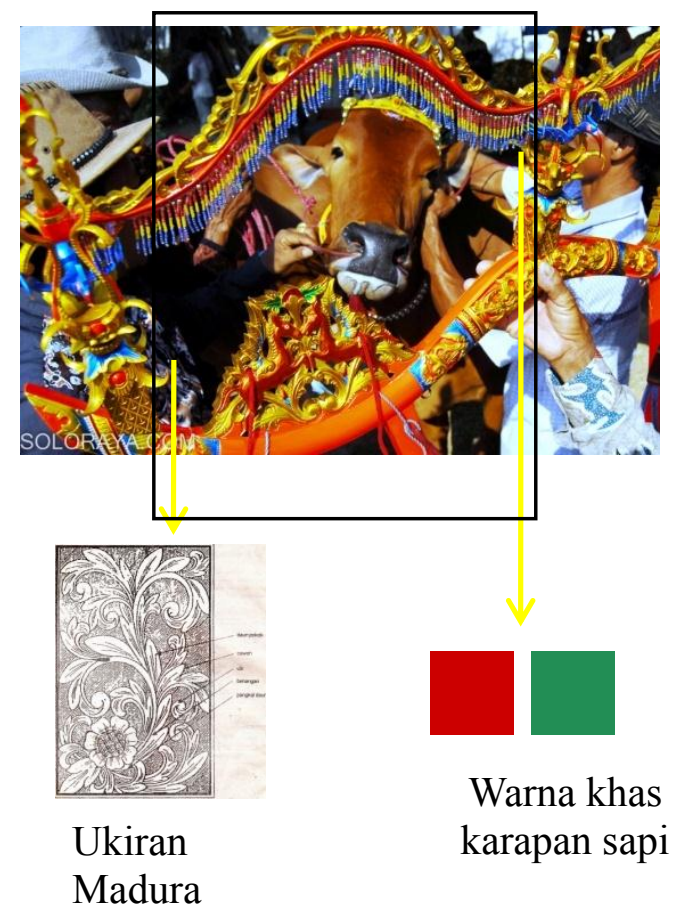

Gambar 3. Konsep Bentukan karapan sapi

(Sumber : Dokumen Pribadi)

Ide rancangan yang diambil dari karakter terkuat dari budaya Madura yaitu berupa karapan sapi dan rumah Madura yang nantinya diharapkan dapat diterapkan dan menjadi cirri khas budaya pada elemen interior restoran.

Pada budaya karapan sapi terdapat beberapa hasil budaya seperti ukiran, pecut, dan warna khas Madura. Ukiran Madura memiliki khas tersendiri terutama pada ukirn daunnya yang seperti gergaji danujung daunnya berikal terdapat seperti sobekan sobekan daun yang bertingkat dari pangkal daun smpai dengan ujung daun yang berbentuk ikal tersebut. (Sumber: artkimianto.blogspot.com)

Untuk rumah Pandalungan (Madura) hal yang paling menonjol adalah penggunaan kayu dan batu bata exspose sebagai material Arsitekturnya. 


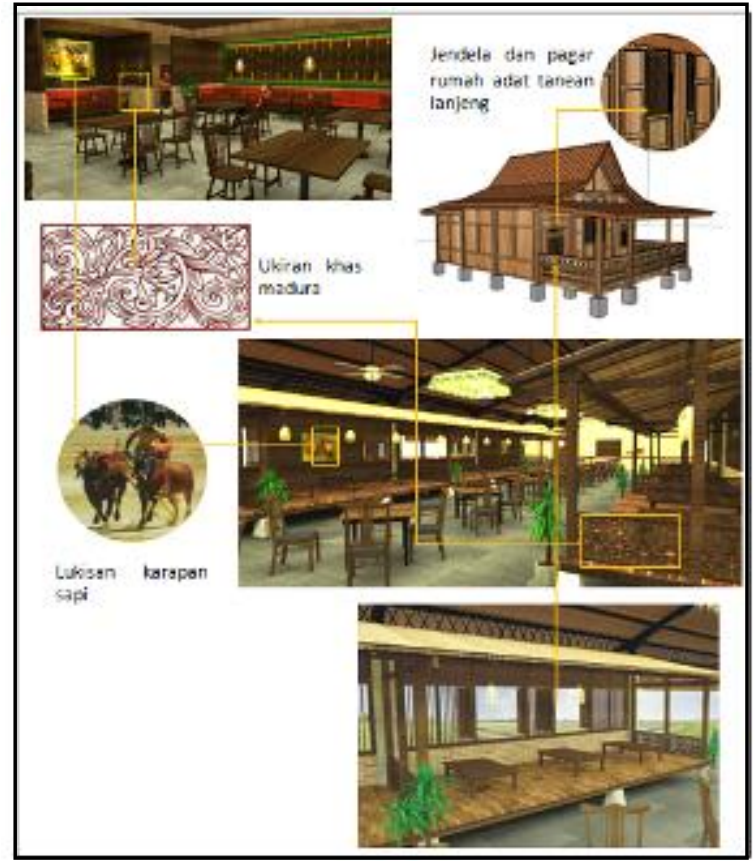

Gambar 4. Konsep Bentukan dari rumah Madura (Sumber : Dokumen Pribadi)

\section{3) Konsep Pencahayaan}

Konsep pencahayaan pada ruangan adalah dengan pencahayaan alami dan buatan. Pencahayaan alami didapatkan dari jendela-jendela besar pada area VIP dan bukaan pada area makan umum. Selain sebagai sumber cahaya alami, jendela pada kamar juga dimaksudkan agar tamu dapat menikmati suasan pulu Pencahayaan buatan yang digunakan adalah general light dengan downlight dan hanging lamp.

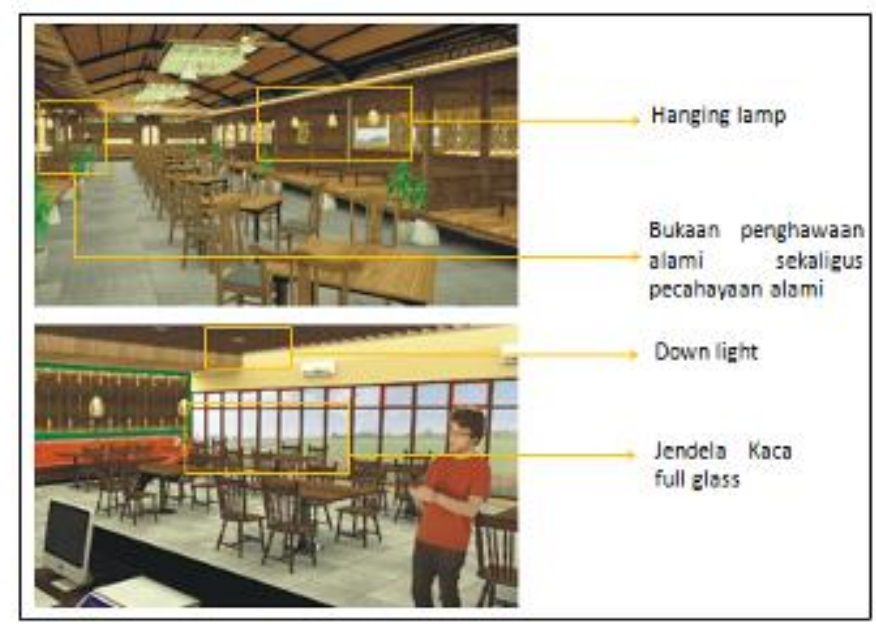

Gambar 5. Konsep Bentukan dari rumah Madura (Sumber : Dokumen Pribadi)

\section{4) Konsep Penghawaan}

Penghawaan pada ruangan menggunakan penghawaan buatan dan alami. Sumber penghawaan alami didapatkan dari jendeladan bukaan, sedangkan penghawaan buatan dengan menggunakan Air Conditioning system. Sistem AC yang digunakan adalah AC split .

\section{DESAIN AKHIR}

A. Layout-Area Makan VIP

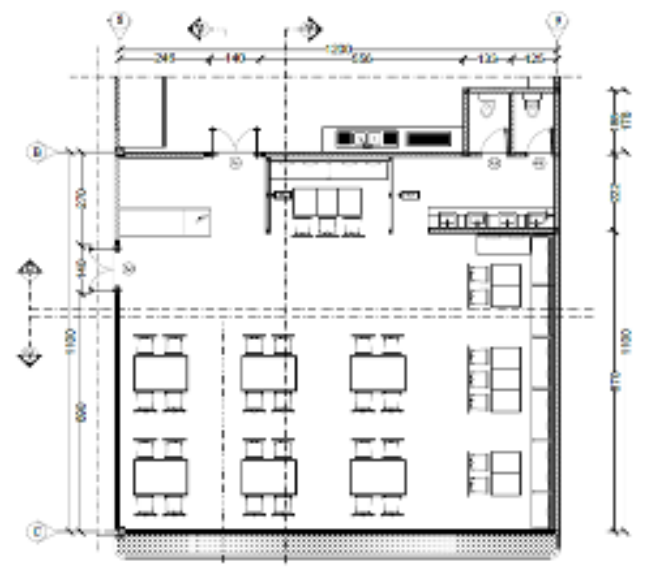

Gambar 6. Layout area makan VIP

(Sumber : Dokumen Pribadi)

Area makan VIP terletak disebelah timur bagian depan restoran Bebek Sinjay, memiliki kapasitas 60 orang atau $15 \%$ dari kapasitas seluruh ruang. Ruangan ini memiliki fasilitas ruang berAC, wastafel, toilet, kasir VIP, meja, kursi, dan sofa panjang. Memiliki luas $12 \times 11 \mathrm{~m}$, area ini dapat dipesan untuk acara acara tertentu.

Layout dari meja di ruang makan VIP disusun sesuai dengan ergonomi, hal tersebut ditujukan agar kenyamanan lebih didapatkan oleh pengunjung yangberada di ruang VIP. Jarak antar meja pada area VIP dibuat agak berjauhan supaya privasi antar pengunjung tercapai.

\section{B. Perspektif}

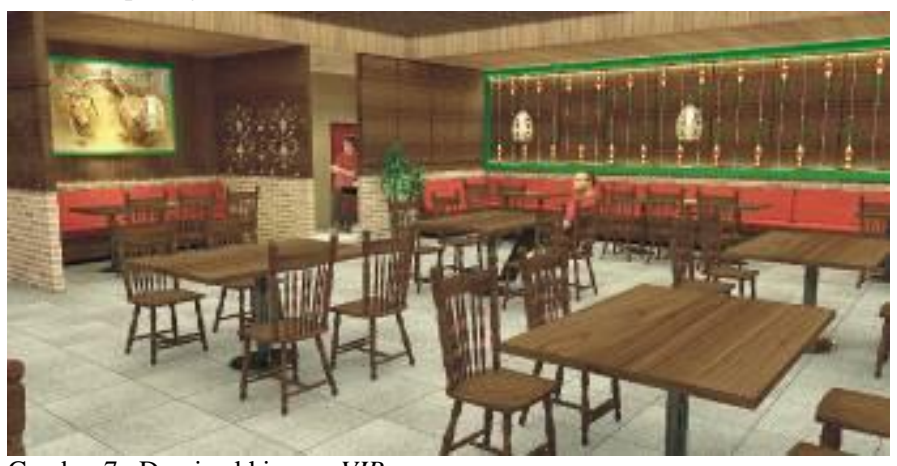

Gambar 7. Desain akhir area VIP

(Sumber : Dokumen Pribadi)

Pada ruang ini memiliki desain dengan warna interior hangat dan menggunakan pencahayaaan buatan melalui hanging lamp dan down light dengan warna cahaya hangat. Desain Interior yang bertemakan tradisional Madura ini menggunakan dinding dari tick wood, agar tampak seperti papan kayu pada rumah rumah adat Madura.

Material yang digunakan mayoritas adalah kayu dan warna warna yang hangat seperti krem dan coklat muda sebagai pendukung konsep tradisional. 


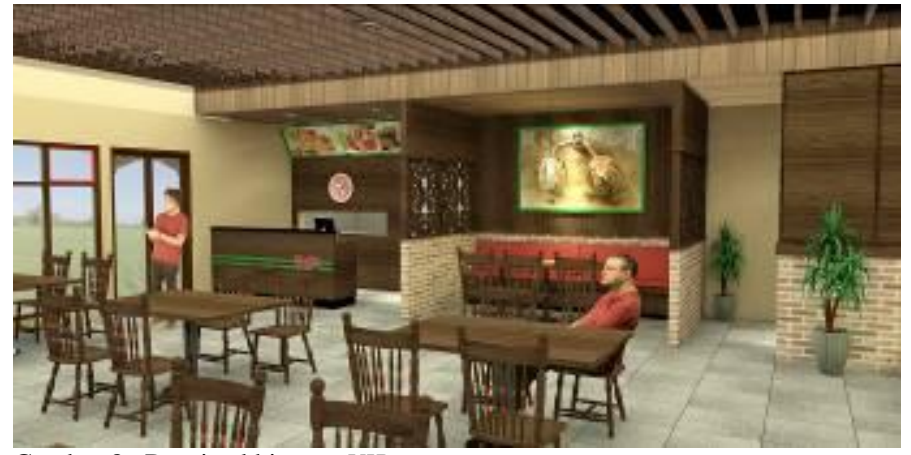

Gambar 8. Desain akhir area VIP

(Sumber : Dokumen Pribadi)

a. Kursi Makan

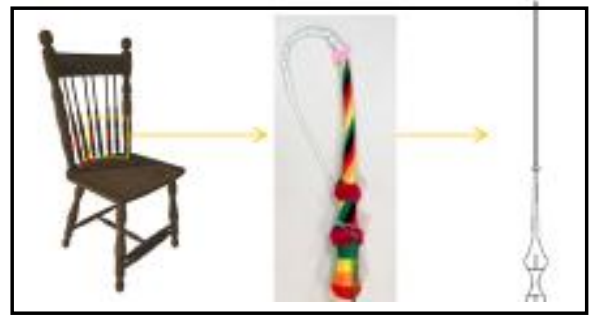

Gambar 9. Desain Kursi Makan

(Sumber : Dokumen Pribadi)

Furnitur pada area VIP yaitu kursi yang didesain custom dengan sandaran transformasi dari pecut Madura. kursi ini menggunakan full kayu solid dengan finishing natural coating dan pada sandaran diberi cat warna merah dan hijau.

\section{b. Partisi Ukiran Madura}

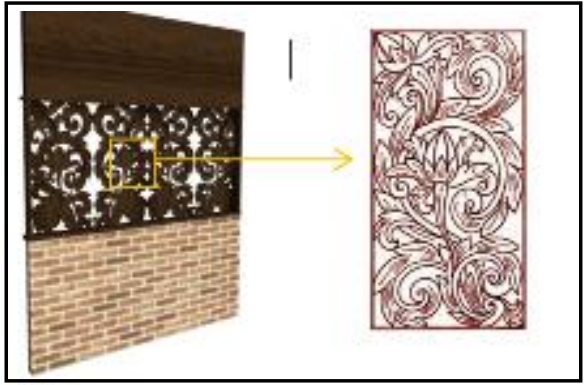

Gambar 10. Partisi Ukiran Madura

(Sumber : Dokumen Pribadi)

Elemen estetis pada area VIP yaitu ukiran Madura yang ada pada partisi antara area wastafel dan area makan. Elemen estetis ini terbuat multiplek yang di cutting laser dengan inishing dark natural coating sebagai pendukung konsep tradisional.

\section{KESIMPULAN}

Kesimpulan yang dapat diambil dari seluruh pembahasan adalah sebagai berikut:

1) Restoran Bebek Sinjay merupakan restoran informal jenis family restaurant.
2) Sebagai restoran yang berasal dari Madura, bebek sinjay seharusnya memiliki karakter khas budaya madura

3) Konsep secara umum yang akan digunakan pada desain interior Restoran Bebek Sinjay Madura adalah mencoba menghadirkan budaya daerah setempat yaitu budaya Madura khususnya karapan sapid an rumah adat madura.

4) Unsur budaya yang diaplikasikan ke dalam desain interior hotel dapat melestarikan budaya, memperkenalkan budaya setempat kepada para wisatawan baik lokal maupun mancanegara, juga dapat mengembangkan sektor pariwisata dalam peningkatan mutu dan kualitas.

5) Kehadiran suatu konsep sebagai tema dalam rancangan tidak hanya untuk memenuhi kenyamanan dan keindahan saja namun akan membuat orang untuk menceritakan pengalamannya dan menjadi sebuah langkah promosi.

6) Fasilitas toko souvenir atau oleh oleh sebaiknya ada di Restoran untuk memfasilitasi kebutuhan para tamu di Restoran tersebut

7) Aktifitas dan kebutuhan pengunjung diperhatikan dan dianalisa lebih lanjut sehingga dapat menghasilkan rancangan mengenai sirkulasi dan penzoningan area yang optimal yang dapat menunjang efektifitas dan kenyamanan pengunjung Restoran Bebek Sinjay.

\section{DAFTAR PUSTAKA}

[1] Wardhana, Mahendra. Menciptakan Estetika dengan Metodologi Penelitian

[2] WA, Marsum. Restoran dan Segala Permasalahnnya. Yogyakarta: Andi Offset. 2005.

[3] Dinas Kebudayaan Pariwisata Pemuda dan Olahraga Kabupaten Sumenep. Sumenep The Heart of Madura: Pesona Wisata Kabupaten Sumenep. Kabupaten Sumenep

[4] Nurmianto, Eko. Ergonomi: Konsep Dasar dan Aplikasinya (edisi kedua). Surabaya: Guna Widya. 2004

[5] Neufert, Ernst. Data Arsitek jilid 1. Jakarta: Erlangga. 1996

[6] Keputusan Menteri Pariwisata, Pos, dan Telekomunikasi No.KN.73/PVVI05/MPPT-85 tentang Peraturan usaha Rumah Makan

[7] Peraturan Menteri Kesehatan RI No. 304/Menkes/Per/89 tentang persyaratan rumah makan

[8] S.K. Memparpostel No.KM. 37/PW,304/MPPT 86 Tanggal 27 Juni1996, tentang syarat sebuah rumah makan

[9] Rosyidi, Hafidz.2016."Menengok Keunikan Rumah Adat Madura”. Tersedia :http://www.satujam.com/rumah-adat-madura/ [diakses : 4 Maret 2017]

[10] Anonim.2015. "Peluang Investasi di Madura". Tersedia :http://www.kompasiana.com/berbenahdiri/peluang-investasi-dimadura_5520c5e28133116b7419fb7c [diakses : 10 Februari 2017]

[11] Anonim.2016. "Definsi Restoran". Tersedia :http://karyatulisilmiah.com/definisi-restoran/ [diakses : 20 Januari 2017]

[12] Anonim. "7 Ciri Interior Rumah Bergaya Tradisional". ROOANG

[13] Anonim.2008."Bab II Studi Pustaka". Tesedia:http://ejournal.uajy.ac.id/1271/3/2MM01568.pdf [diakses : 5 Februari 2017]

[14] Anonim.2014." Kenali Teori Warna Dasar Untuk Mengetahui Apa Yang Terlihat Bagus". Tertulis http://www.tahupedia.com/content/show/497/Kenali-Teori-WarnaDasar-Untuk-Mengetahui-Apa-Yang-Terlihat-Bagus [diakses : 5 Februari 2017] 